\title{
ANÁLISE DO RESFRIAMENTO DA SOLUÇÃO NUTRITIVA PARA CULTIVO HIDROPÔNICO DO MORANGUEIRO ${ }^{1}$
}

\author{
LUIZ V. E. VILLELA JÚNIOR ${ }^{2}$, JAIRO A. C. DE ARAÚJO ${ }^{3}$, THIAGO L. FACTOR ${ }^{4}$
}

RESUMO: Este trabalho teve como objetivo a produção hidropônica de morangos com resfriamento da solução nutritiva, em Jaboticabal - SP. O experimento foi conduzido no Setor de Plasticultura do Departamento de Engenharia Rural da FCAV/UNESP, Câmpus de Jaboticabal, em casa de vegetação coberta com filme de polietileno, sendo o transplantio realizado em 9-1-2002. Foram avaliadas duas variedades de morango: Campinas e "Sweet Charlie", cultivadas em sistema hidropônico tipo NFT, com ou sem resfriamento da solução nutritiva. A solução nutritiva resfriada foi mantida à temperatura de aproximadamente $12^{\circ} \mathrm{C}$, por meio de um trocador de calor. A variedade "Sweet Charlie" apresentou melhores resultados para peso médio dos pseudofrutos, diâmetro médio longitudinal, diâmetro médio transversal, número médio de pseudofrutos e produtividade. $\mathrm{O}$ resfriamento da solução nutritiva conferiu maior número de pseudofrutos colhidos, maior produtividade e maior teor de sólidos solúveis totais aos pseudofrutos da variedade "Sweet Charlie". No entanto, o resfriamento da solução nutritiva não causou efeitos sobre a variedade Campinas.

PALAVRAS-CHAVE: Fragaria $x$ ananassa Duch., NFT, hidroponia.

\section{NUTRIENT SOLUTION COOLING EVALUATION FOR HYDROPONIC CULTIVATION OF STRAWBERRY PLANT}

SUMMARY: This work had as its major aim the hydroponic production of strawberries with the cooling of the nutrient solution, in Jaboticabal - SP - Brazil. The experiment was conducted in a covered greenhouse with a plastic film and seed transplantation achieved on January 9, 2002. Two varieties of strawberries were evaluated: Campinas and Sweet Charlie, both cultivated under the hydroponic system NFT type with or without cooling the nutrient solution. The cooling of the nutrient solution at about $12{ }^{\circ} \mathrm{C}$ was in a heating exchange device. The Sweet Charlie variety presented the best results for both the average weight and number of pseudofruit, longitudinal average diameter, cross average diameter, average number of pseudofruit and productivity. The cooling of the nutrient solution confered greater number of pseudofruit collected and better productivity of Sweet Charlie variety. However, the cooling of the nutrient solution didn't cause any effects over the Campinas variety.

KEYWORDS: Fragaria $x$ ananassa Duch., NFT, hydroponics.

\footnotetext{
${ }^{1}$ Trabalho financiado pela FAPESP (Processo No 98/6889-8)

${ }^{2}$ Eng. Agrônomo, M.Sc., Doutorando em Agronomia pelo Programa de Pós-Graduação em Produção Vegetal, FCAV/UNESP, Jaboticabal - SP, Fone: (0XX16) 3209 2637, e-mail: villelajr@zipmail.com.br

${ }^{3}$ Eng. Agrônomo, Prof. Adjunto, FCAV/UNESP, Departamento de Engenharia Rural, e-mail: jaca@ fcav.unesp.br

${ }^{4}$ Eng. Agrônomo, M.Sc., Doutorando em Agronomia pelo Programa de Pós-Graduação em Produção Vegetal, FCAV/UNESP, email: factor@fcav.unesp.br

Recebido pelo Conselho Editorial em: 23-6-2003

Aprovado pelo Conselho Editorial em: 25-5-2004
} 


\section{INTRODUÇÃO}

A sazonalidade da produção de morangos no Brasil é um dos principais problemas da cultura, haja vista que esses pseudofrutos levados ao mercado em época de entressafra têm seu preço elevado. Por isso, a antecipação da colheita visando a colocar o produto no mercado na época de maior retorno econômico, permitirá a expansão da cultura do morangueiro para regiões de clima mais quente.

No Brasil, poucos estudos têm sido realizados para determinar o comportamento da cultura em condições de clima mais quente. Segundo PASSOS (1999) e CAMARGO \& PASSOS (1993), as cultivares de morangueiro atualmente utilizadas no País comportam-se como de dias curtos, ou seja, necessitam de diminuição do fotoperíodo e da temperatura para iniciar a floração e a frutificação.

Para cada função vital do morangueiro, existem temperaturas ótimas e críticas. Em temperaturas acima de $10{ }^{\circ} \mathrm{C}$ e comprimento do dia maior ou igual a 12 horas, a planta tende a vegetar com aumento da produção de estolhos. Temperaturas abaixo de $20^{\circ} \mathrm{C}$ favorecem o desenvolvimento floral; em torno de $25{ }^{\circ} \mathrm{C}$, inibem a diferenciação floral e acima de $32{ }^{\circ} \mathrm{C}$ podem causar o abortamento floral. Existem também diferenças comportamentais dos clones cultivados em relação às condições climáticas (RONQUE, 1998).

A época ideal de plantio varia em função das condições de temperatura de cada região, ficando estabelecida forte relação entre altitude e época recomendada para plantio. RONQUE (1998) propôs três épocas em função da altitude média: menor que $600 \mathrm{~m}$ - plantio de abril a maio; entre 600 e $700 \mathrm{~m}$ - plantio em abril, e maior que $700 \mathrm{~m}$ - plantio no final de fevereiro e março. Com isso, fica evidente que, em regiões mais quentes, o plantio deve ser mais tardio e, em regiões mais frias, o plantio deve ser mais precoce.

O crescimento da demanda pelo morango no Brasil e no mundo vem despertando o interesse por novas e melhores técnicas de cultivo, procurando-se aumentar a produtividade e, conseqüentemente, a lucratividade dessa cultura. $\mathrm{O}$ cultivo do morangueiro por quase todo o ano, sob ambiente protegido, é uma alternativa para os clássicos problemas: produção concentrada em alguns meses, escassez de mãode-obra, qualidade de pseudofrutos e pouca lucratividade (LIETEN, 1993).

A hidroponia surgiu como uma técnica altamente racional, na qual se consegue uma otimização do uso da água, do espaço, do tempo, dos nutrientes e da mão-de-obra (CASTELLANE \& ARAÚJO, 1994). Com o passar do tempo, desenvolveram-se algumas variantes do cultivo hidropônico, entre essas destaca-se o tipo NFT ("Nutrient Film Technique"). Segundo FOSSATI (1986), no sistema NFT, a planta se desenvolve com dois terços de seu sistema radicular submerso na solução nutritiva, fornecida à planta sob a forma de um fluxo intermitente, de onde ela retira os nutrientes, enquanto a porção restante do sistema radicular se desenvolve ao ar livre para a absorção de oxigênio. O sistema NFT é aplicado atualmente em um grande número de culturas, entre elas: alface, brócolis, feijãovagem, repolho, couve-chinesa, salsa, meloeiro, agrião, pepino, berinjela, pimentão, tomateiro e morangueiro (LINARDAKIS \& MANIOS, 1991; CASTELLANE \& ARAÚJO, 1994; VILLELA JÚNIOR et al., 2003). Esta técnica foi adaptada para morangos na Inglaterra, Bélgica e Holanda, no início dos anos de 1980.

Quanto ao diâmetro dos canais de cultivo para a cultura do morangueiro em sistema hidropônico tipo NFT, TAKEDA (1999), GUSMÃO (2000) e FERNANDES JÚNIOR (2001) utilizaram tubos de PVC com $100 \mathrm{~mm}$ de diâmetro, alcançando bons resultados. FURLANI et al. (1999) relatam que a capacidade volumétrica do reservatório da solução nutritiva está diretamente relacionada ao número de plantas e à espécie a ser cultivada. Para o cultivo do morangueiro, esses autores recomendam um volume entre 0,5 e 1,0 litro por planta, ressaltando que, quanto maior a relação entre volume de solução nutritiva e número de plantas, menores serão as variações físico-químicas da solução nutritiva. 
No Brasil, GUSMÃO (2000), cultivando hidroponicamente o morangueiro em Jaboticabal - SP, em época considerada favorável (julho a novembro), conseguiu uma produtividade total de 1.070 e $2.450 \mathrm{~g} \mathrm{~m}^{-2}$ para as cultivares "Seascape" e Campinas, respectivamente. No entanto, o autor relatou uma progressiva morte das plantas a partir do início de novembro, época de menor oferta de morango no mercado nacional.

Em condições de clima tropical, no qual ocorrem altas temperaturas e grande incidência de luz, normalmente há redução no crescimento de plantas de clima ameno se a temperatura da zona radicular não for controlada (LEE \& CHEONG, 1996; HE \& LEE, 1998). A técnica do NFT é a que proporciona a maneira mais eficiente de controlar a temperatura das raízes, independentemente da temperatura da parte aérea das plantas. Segundo MORGAN (2002), em sistemas de cultivo hidropônico, a temperatura da solução nutritiva está intimamente relacionada com a quantidade de oxigênio $\left(\mathrm{O}_{2}\right)$ dissolvido na solução. Com o aumento da temperatura da solução, o $\mathrm{O}_{2}$ dissolvido, que estava "aprisionado", desprende-se.

NEWMAN \& DAVIS (1988) afirmam que ocorre aumento da condutividade hidráulica das raízes das plantas quando a temperatura nessa região é adequada. DODD et al. (2000), estudando a cultura do pimentão submetida a diferentes temperaturas da solução nutritiva, sob condições de cultivo hidropônico, concluíram que houve aceleração do crescimento da cultura quando exposta à temperatura de $20^{\circ} \mathrm{C}$, quando comparada à temperatura de $30^{\circ} \mathrm{C}$. Com relação à cultura do morangueiro, não foram encontrados trabalhos na literatura, com referência ao resfriamento da solução nutritiva em cultivos hidropônicos.

Como pode ser visto, o cultivo hidropônico do morangueiro, no Brasil, necessita de novas pesquisas, principalmente com o objetivo de procurar técnicas que possam possibilitar colheitas em épocas e locais onde a oferta do produto é pequena e, conseqüentemente, o lucro alto. Dentro desse enfoque, desenvolveu-se o presente trabalho de pesquisa com o objetivo de cultivar o morangueiro em condições hidropônicas com resfriamento da solução nutritiva.

\section{MATERIAL E MÉTODOS}

O ensaio foi conduzido no Setor de Plasticultura do Departamento de Engenharia Rural da FCAV/UNESP - Câmpus de Jaboticabal, localizado na latitude $21^{\circ} 15^{\prime} 22^{\prime \prime}$ S e longitude 48 $18^{\prime} 58^{\prime \prime} \mathrm{W}$, com altitude média de $595 \mathrm{~m}$. O clima da região, segundo classificação de Köeppen, é do tipo Cwa, subtropical, relativamente seco no inverno e com chuvas no verão, apresentando temperatura média anual de $22^{\circ} \mathrm{C}$ e precipitação média anual de $1.552 \mathrm{~mm}$ (VOLPE et al., 1989).

O cultivo foi realizado em casa de vegetação do tipo capela, com $3 \mathrm{~m}$ de pé-direito, $51 \mathrm{~m}$ de comprimento, $10 \mathrm{~m}$ de largura, coberta com filme de polietileno de baixa densidade, com aditivo ultravioleta e espessura de $150 \mu \mathrm{m}$. Por cima do filme de polietileno, foi colocada uma tela de polipropileno refletora de luz com $50 \%$ de sombreamento e, nas laterais, utilizaram-se telas de polipropileno com $30 \%$ de sombreamento e $1 \mathrm{~m}$ de altura.

O cultivo ocorreu em quatro bancadas, com 12,0 $\mathrm{m}$ de comprimento e 2,0 $\mathrm{m}$ de largura cada, à altura média de 1,0 $\mathrm{m}$ do nível do solo. O espaçamento adotado foi de 0,30 x 0,30 $\mathrm{m}$, com densidade de 10 plantas por $\mathrm{m}^{2}$. Em cada bancada, foram montados seis canais de cultivo, os quais foram compostos por tubos de PVC com $100 \mathrm{~mm}$ de diâmetro, cortados longitudinalmente e remontados sobre as bancadas metálicas com declividade de 2 a 2,5\%, para que a solução nutritiva pudesse ser escoada por gravidade. Os canais de cultivo, por sua vez, foram recobertos com placas de PVC com $1 \mathrm{~mm}$ de espessura e perfuradas com orifícios de $50 \mathrm{~mm}$ de diâmetro, espaçados de $0,30 \times 0,30 \mathrm{~m}$, onde as plantas foram afixadas. 
Utilizou-se o delineamento experimental em blocos casualizados e esquema de análise de variância fatorial 2 x 2 (duas variedades e duas temperaturas da solução nutritiva), com dez repetições, sendo cada parcela formada por 24 plantas.

As variedades de morangueiro (Fragaria $x$ ananassa Duch) estudadas foram: Campinas e "Sweet Charlie". A variedade Campinas (IAC 2712) é indicada para consumo in natura, pois possui sabor adocicado, tendo entre outras características a precocidade e boa produtividade. Seus pseudofrutos são graúdos, cônico-alongados, têm firmeza regular na época quente e coloração vermelho-brilhante. A variedade "Sweet Charlie" é considerada precoce e de boa produtividade, atendendo às exigências do mercado in natura, apresentando pseudofrutos vistosos, graúdos, cônicoalongados, vermelho-claros e brilhantes, de sabor suave-adocicado e firmes. As mudas, certificadas quanto à isenção de doenças, foram adquiridas da empresa "Multiplanta", em Andradas - MG, tendo sido transplantadas para as bancadas de cultivo, com três a quatro folhas, no dia 9-1-2002. Os tratos culturais realizados foram: retirada de folhas velhas, retirada de estolhos e tratos fitossanitários, sempre comuns aos quatro tratamentos.

A solução nutritiva utilizada foi a indicada por CASTELLANE \& ARAÚJO (1994) para a cultura do morangueiro, com 149,00; 47,04; 169,78; 133,00;24,60;43,20; 2,52; 0,45;0,21;0,25; 0,02; $0,05 \mathrm{mg} \mathrm{L}^{-1}$ de N, P, K, Ca, Mg, S, Fe, Mn, B, Zn, Cu e Mo, respectivamente. Depois de preparada, a solução nutritiva apresentou, em média, $\mathrm{pH} 6,2$ e condutividade elétrica de $1,7 \mathrm{mS} \mathrm{cm}^{-1}$.

A solução nutritiva foi conduzida até os canais de cultivo por meio de dois conjuntos motobombas, onde retornava por gravidade até duas caixas de polietileno, cada uma com capacidade para $1.000 \mathrm{~L}$, a partir das quais era novamente bombeada, formando, com isso, um sistema fechado. Para acionar o sistema de bombeamento da solução nutritiva, foram utilizados temporizadores. Durante as horas menos quentes do dia (das 6 às $10 \mathrm{~h}$ e das 17 às $18 \mathrm{~h} 30 \mathrm{~min}$ ), irrigou-se 15 minutos com intervalos de 30 minutos, enquanto nas horas mais quentes (das 10 h15 min às 16 h 45 min), irrigou-se 15 minutos com intervalos de 15 minutos. À noite irrigou-se apenas duas vezes durante 15 minutos, às 20 h 30 min e às 0 h 30 min (CASTELLANE \& ARAÚJO, 1994). As vazões utilizadas nos canais de cultivo foram de aproximadamente $1,5 \mathrm{~L} \mathrm{~min}^{-1}$, seguindo o recomendado por ALPI \& TOGNONI (1991), citados por CASTELLANE \& ARAÚJO (1994).

Em relação ao manejo da solução nutritiva, completou-se o volume das caixas d'água todos os dias até $1.000 \mathrm{~L}$ e, de $7 \mathrm{em} 7$ dias, fez-se a troca completa da solução nutritiva (CASTELLANE \& ARAÚJO, 1994).

Nos tratamentos em que a solução nutritiva era resfriada, a temperatura permaneceu em torno de $12{ }^{\circ} \mathrm{C}$. Para tanto, utilizou-se um resfriador desenvolvido na empresa Friocal da cidade de Valinhos SP, denominado de trocador de calor, que, por meio de um sensor localizado no interior do reservatório de solução nutritiva, mantinha a temperatura no valor desejado. Nos tratamentos em que a solução nutritiva não era resfriada, a temperatura permaneceu ambiente.

Para melhor compreensão do desenvolvimento da cultura, foi realizado o monitoramento de alguns elementos micrometeorológicos durante a execução do ensaio. Para isso, instalou-se um coletor de dados ("datalogger") da marca Campbell Scientific Inc., modelo CR 10X. Foram coletados os dados de temperatura em todos os canais de cultivo e temperatura do ar a 1,5 $\mathrm{m}$ de altura, no centro da casa de vegetação. Para a obtenção dos dados, utilizaram-se termopares de cobre-constantan conectados ao "datalogger". Os sensores utilizados foram termopares do tipo T, soldados com estanho e recobertos com adesivo líquido da marca Polyepox para que ficassem protegidos contra a oxidação e a corrosão causada pela solução nutritiva. Esses sensores foram instalados no centro de todas as parcelas, de modo que ficassem paralelos ao fundo dos canais de cultivo, recobertos pelo sistema radicular das plantas e pela solução nutritiva. 
Quanto à cultura, foram avaliados: número de pseudofrutos colhidos, produtividade total de pseudofrutos $\left(\mathrm{g} \mathrm{m}^{-2}\right)$, peso médio dos pseudofrutos $(\mathrm{g})$, diâmetros longitudinal e transversal dos pseudofrutos $(\mathrm{mm})$. Quanto às características tecnológicas dos pseudofrutos, foram avaliados: teor de sólidos solúveis totais do suco ( ${ }^{\circ}$ Brix), acidez total titulável do suco (g de ácido cítrico/100 mL de suco) e pH do suco.

\section{RESULTADOS E DISCUSSÃO}

As temperaturas médias diárias do ar no interior do ambiente protegido durante o período de estudo variaram de 19,4 a $32,7^{\circ} \mathrm{C}$, sendo a média de $26,7^{\circ} \mathrm{C}$. Os canais de cultivo que receberam a solução nutritiva na temperatura ambiente apresentaram temperaturas médias diárias de 19,99 a $25,60{ }^{\circ} \mathrm{C}$, sendo a média de $22,90^{\circ} \mathrm{C}$. Já os canais de cultivo que receberam a solução nutritiva resfriada, tiveram uma variação de temperaturas médias diárias de 12,82 a $16,45^{\circ} \mathrm{C}$, sendo a média de $14,75^{\circ} \mathrm{C}$. Nota-se que os canais de cultivo que receberam a solução nutritiva resfriada, apresentaram temperaturas médias diárias menores, em comparação aos canais que receberam a solução nutritiva à temperatura ambiente.

Na Tabela 1, pode-se observar o peso médio dos pseudofrutos, os diâmetros médios longitudinal e transversal dos pseudofrutos, o número médio de pseudofrutos colhidos por metro quadrado e a produtividade média obtida do morangueiro cultivado em hidroponia tipo NFT. Verifica-se que o peso médio dos pseudofrutos da variedade "Sweet Charlie" foi de 11,70 g, superando significativamente o peso médio dos pseudofrutos obtidos da variedade Campinas, que foi de 7,71 g. Essa diferença pode estar associada a um fator genético, a efeitos das condições do experimento ou ainda a uma interação desses fatores. Quanto ao resfriamento ou não da solução nutritiva, não foram observadas diferenças significativas em relação ao peso médio dos pseudofrutos colhidos.

As médias dos diâmetros longitudinais e transversais dos pseudofrutos seguiram uma relação direta com o peso médio desses, e os valores obtidos dos pseudofrutos produzidos pela variedade "Sweet Charlie" superaram a variedade Campinas (Tabela 1). Seria esperado que os pseudofrutos da variedade "Sweet Charlie", por apresentar maior número colhido por metro quadrado (Tabela 1), tivessem um menor tamanho, uma vez que um grande número de drenos (pseudofrutos) resulta em redução na disponibilidade de assimilados (LARCHER, 1986). Por outro lado, CUNHA \& BIAGGIANI (1990) e RONQUE (1998) afirmam que o tamanho dos pseudofrutos é um fator inerente a cada variedade.

A relação média entre os diâmetros longitudinal e transversal permite o conhecimento do formato médio dos pseudofrutos, sendo que valores próximos a 1 indicam frutos mais achatados e valores distantes de 1 , frutos mais alongados. O conhecimento desse índice é importante para a definição da embalagem e do arranjo dos frutos. Além disso, essa característica influencia na classificação e padronização dos morangos, podendo determinar a melhor aceitação e valorização do produto para determinados tipos de mercado. Se calcularmos as relações entre os diâmetros longitudinais (DL) e transversais (DT) para cada variedade estudada, pode-se observar que os pseudofrutos da variedade Campinas apresentaram relação média de 1,24, enquanto os pseudofrutos da variedade "Sweet Charlie" apresentaram relação média de 1,07. Com isso, pode-se concluir que as variedades estudadas apresentaram pseudofrutos com formatos diferenciados, sendo que os produzidos pela variedade Campinas apresentaram formato médio mais alongado, e os produzidos pela variedade "Sweet Charlie" apresentaram formato médio mais achatado.

O resfriamento da solução nutritiva não alterou significativamente os diâmetros transversal e longitudinal dos pseudofrutos de morangueiro produzidos em hidroponia tipo NFT, nas condições da presente pesquisa (Tabela 1). 
TABELA 1. Peso médio dos pseudofrutos (PM), diâmetros médios longitudinal (DL) e transversal (DT) dos pseudofrutos, número médio de pseudofrutos colhidos por metro quadrado (NM) e produtividade (PD) do morangueiro cultivado em hidroponia tipo NFT.

\begin{tabular}{|c|c|c|c|c|c|}
\hline & $\begin{array}{l}\text { PM } \\
(\mathrm{g})\end{array}$ & $\begin{array}{c}\mathrm{DL} \\
(\mathrm{mm})\end{array}$ & $\begin{array}{c}\text { DT } \\
(\mathrm{mm})\end{array}$ & NM & $\begin{array}{c}\mathrm{PD} \\
\left(\mathrm{g} \mathrm{m}^{-2}\right)\end{array}$ \\
\hline \multicolumn{6}{|l|}{ Variedades (V) } \\
\hline Campinas & $7,71 \mathrm{~B}^{1}$ & $29,73 \mathrm{~B}$ & $24,03 \mathrm{~B}$ & $13,32 \mathrm{~B}$ & $107,40 \mathrm{~B}$ \\
\hline "Sweet Charlie" & $11,70 \mathrm{~A}$ & $33,92 \mathrm{~A}$ & $31,73 \mathrm{~A}$ & $83,48 \mathrm{~A}$ & $967,85 \mathrm{~A}$ \\
\hline Teste $\mathrm{F}$ para $\mathrm{V}$ & $52,63 * *$ & $22,54 * *$ & $92,90 * *$ & $92,85 * *$ & $159,79 * *$ \\
\hline \multicolumn{6}{|c|}{ Temperatura da Solução Nutritiva (T) } \\
\hline Temperatura ambiente & $9,73 \mathrm{~A}$ & $32,28 \mathrm{~A}$ & $27,63 \mathrm{~A}$ & $33,88 \mathrm{~B}$ & $381,01 \mathrm{~B}$ \\
\hline Resfriada & $9,67 \mathrm{~A}$ & $31,36 \mathrm{~A}$ & $28,13 \mathrm{~A}$ & $62,93 \mathrm{~A}$ & $694,24 \mathrm{~A}$ \\
\hline Teste F para $\mathrm{T}$ & $0,01^{\mathrm{NS}}$ & $1,08^{\mathrm{NS}}$ & $0,40^{\mathrm{NS}}$ & $15,92 * *$ & $21,17 * *$ \\
\hline Teste F para Interação VxT & $0,27^{\mathrm{NS}}$ & $1,81^{\mathrm{NS}}$ & $1,07^{\mathrm{NS}}$ & $10,87 * *$ & $16,34 * *$ \\
\hline Teste F para blocos & 1,16 & $0,56^{\mathrm{NS}}$ & $0,68^{\mathrm{NS}}$ & $0,34^{\mathrm{NS}}$ & $0,48^{\mathrm{NS}}$ \\
\hline
\end{tabular}

${ }^{\mathrm{T}}$ Valores seguidos das mesmas letras nas colunas não diferem entre si, pelo teste de Tukey, a 5\% de probabilidade.

** Significativo pelo teste $\mathrm{F}$ a $1 \%$ de probabilidade.

NS Não significativo pelo teste $\mathrm{F}$.

Em relação ao número médio de pseudofrutos colhidos por metro quadrado, houve interação significativa entre as variedades e as temperaturas das soluções nutritivas estudadas, com diferenças significativas entre as médias dos tratamentos, sendo que a variedade "Sweet Charlie" superou a variedade Campinas, e a solução nutritiva resfriada superou a solução nutritiva sem resfriamento (Tabela 1). Pela Tabela 2, pode-se visualizar o desdobramento das médias do número de pseudofrutos colhidos por metro quadrado do morangueiro cultivado em hidroponia tipo NFT.

TABELA 2. Desdobramento das médias do número de pseudofrutos colhidos por metro quadrado do morangueiro cultivado em hidroponia tipo NFT.

\begin{tabular}{lcrc}
\hline \multirow{2}{*}{ Variedades (V) } & \multicolumn{2}{c}{ Temperatura da Solução Nutritiva (T) } & \multirow{2}{*}{ Teste F } \\
\cline { 2 - 3 } & Temperatura Ambiente & Resfriada & \\
\hline Campinas & $10,80 \mathrm{Ba}^{\mathrm{I}}$ & $15,85 \mathrm{Ba}$ & $0,24^{\mathrm{NS}}$ \\
Sweet Charlie & $56,95 \mathrm{Ab}$ & $110,00 \mathrm{Aa}$ & $26,55^{* *}$ \\
\hline Teste F & $20,09 * *$ & $83,63 * *$ \\
\hline DMS & \multicolumn{3}{c}{21,13} \\
C.V. $(\%)$ & 47,56 \\
\hline
\end{tabular}

${ }^{\mathrm{C}}$ Médias seguidas pela mesma letra maiúscula na coluna e minúscula na linha não diferem entre si.

** Significativo pelo teste $\mathrm{F}$ a $1 \%$ de probabilidade.

NS Não significativo pelo teste F.

O desdobramento das médias do número de pseudofrutos colhidos por metro quadrado observado na Tabela 2 revelou que o resfriamento da solução nutritiva conferiu maior número de pseudofrutos somente para a variedade "Sweet Charlie", não tendo afetado significativamente a variedade Campinas. Esse fato provavelmente está relacionado às diferenças genéticas de cada variedade em relação a diferentes temperaturas do ambiente radicular.

A exemplo do número médio de pseudofrutos, a produtividade média de pseudofrutos também apresentou interação significativa entre as variedades e as temperaturas das soluções nutritivas estudadas, sendo que a variedade "Sweet Charlie" superou a variedade Campinas, e a solução nutritiva resfriada superou a solução nutritiva sem resfriamento (Tabela 1). 
TABELA 3. Desdobramento das médias da produtividade do morangueiro cultivado em hidroponia tipo NFT, em gramas de pseudofrutos por metro quadrado.

\begin{tabular}{lcrc}
\hline \multirow{2}{*}{ Variedades (V) } & \multicolumn{2}{c}{ Temperatura da Solução Nutritiva (T) } & \multirow{2}{*}{ Teste F } \\
& Temperatura Ambiente & Resfriada & $0,16^{\mathrm{NS}}$ \\
\hline Campinas & $88,37 \mathrm{Ba}^{1}$ & $126,42 \mathrm{Ba}$ & $37,36^{* *}$ \\
Sweet Charlie & $673,65 \mathrm{Ab}$ & $1.262,05 \mathrm{Aa}$ & \\
\hline Teste F & $36,96^{* *}$ & $139,16^{* *}$ & \\
\hline DMS & \multicolumn{3}{c}{197,63} \\
CV $(\%)$ & 40,04 & \\
\hline
\end{tabular}

${ }^{\mathrm{T}}$ Médias seguidas pela mesma letra maiúscula na coluna e minúscula na linha não diferem entre si.

** Significativo pelo teste $\mathrm{F}$ a $1 \%$ de probabilidade.

${ }^{\text {NS }}$ Não significativo pelo teste $\mathrm{F}$

O desdobramento das médias da produtividade observada na Tabela 3 permite verificar que a maior produtividade observada quando se utilizou solução nutritiva resfriada somente ocorreu com a variedade "Sweet Charlie", não ocorrendo com a variedade Campinas. A maior produtividade da variedade "Sweet Charlie" está relacionada ao maior número de pseudofrutos colhidos. Deve-se ressaltar que a produtividade média da variedade "Sweet Charlie", quando se utilizou solução nutritiva resfriada $\left(1.262,05 \mathrm{~g} \mathrm{~m}^{-2}\right)$, alcançou valores similares aos valores observados por GUSMÃO (2000), porém em uma época do ano menos favorável para o cultivo do morangueiro.

$\mathrm{Na}$ Tabela 4, pode-se visualizar os valores médios da acidez total titulável, teor de sólidos solúveis totais e $\mathrm{pH}$ do suco extraído de pseudofrutos do morangueiro cultivado em hidroponia tipo NFT. Nota-se que não houve diferença significativa entre os valores médios de acidez total titulável e $\mathrm{pH}$ do suco dos pseudofrutos produzidos pelas variedades Campinas e "Sweet Charlie". Verifica-se, também, que o resfriamento da solução nutritiva não alterou significativamente os valores médios da acidez total titulável e do $\mathrm{pH}$ do suco dos pseudofrutos produzidos.

TABELA 4. Valores médios de acidez total titulável (AC), teor de sólidos solúveis totais (TSST) e pH do suco extraído de pseudofrutos de morangueiro cultivado em hidroponia tipo NFT.

\begin{tabular}{lccc}
\hline Variedades (V) & $\begin{array}{c}\mathrm{AC} \\
\text { (g de ácido cítrico /100 mL de suco) }\end{array}$ & $\begin{array}{c}\text { TSST } \\
\left({ }^{\circ} \text { Brix }\right)\end{array}$ & pH \\
\hline Campinas & $0,5475 \mathrm{~A}$ & $5,32 \mathrm{~B}$ & $3,70 \mathrm{~A}$ \\
"Sweet Charlie" & $0,5050 \mathrm{~A}$ & $5,66 \mathrm{~A}$ & $3,68 \mathrm{~A}$ \\
\hline Teste F para variedades (V) & $4,7725^{\mathrm{NS}}$ & $9,35^{*}$ & $0,36^{\mathrm{NS}}$ \\
\hline Temperatura da Solução Nutritiva (T) & & & \\
\hline Temperatura ambiente & $0,5063 \mathrm{~A}$ & $5,24 \mathrm{~B}$ & $3,69 \mathrm{~A}$ \\
Resfriada & $0,5462 \mathrm{~A}$ & $5,74 \mathrm{~A}$ & $3,69 \mathrm{~A}$ \\
\hline Teste F para temperatura da solução nutritiva & $4,2275^{\mathrm{NS}}$ & $20,51^{* *}$ & $0,31^{\mathrm{NS}}$ \\
\hline Teste F para Interação VxT & $4,2275^{\mathrm{NS}}$ & $13,96^{* *}$ & $0,79^{\mathrm{NS}}$ \\
Teste F para blocos & $0,7761^{\mathrm{NS}}$ & $3,47^{\mathrm{NS}}$ & $1,20^{\mathrm{NS}}$ \\
\hline
\end{tabular}

${ }^{\mathrm{T}}$ Valores seguidos das mesmas letras nas colunas não diferem entre si, pelo teste de Tukey, a 5\% de probabilidade.

* Significativo pelo teste $\mathrm{F}$ a $5 \%$ de probabilidade.

** Significativo pelo teste $\mathrm{F}$ a $1 \%$ de probabilidade.

NS Não significativo pelo teste F.

Em relação aos valores médios do teor de sólidos solúveis totais (TSST), houve interação significativa entre as variedades e as temperaturas das soluções nutritivas estudadas, com diferenças acentuadas entre as médias dos tratamentos (Tabela 4). 
Pela Tabela 5, pode-se visualizar o desdobramento das médias do TSST do suco extraído dos pseudofrutos. A variedade "Sweet Charlie" superou a variedade Campinas, e a solução nutritiva resfriada superou a solução nutritiva sem resfriamento. $\mathrm{O}$ desdobramento das médias revelou que o aumento significativo do TSST no suco dos pseudofrutos, quando se utilizou solução nutritiva resfriada, somente ocorreu com a variedade "Sweet Charlie", não ocorrendo com a variedade Campinas. Com isso, pode-se dizer que os pseudofrutos da variedade "Sweet Charlie" apresentaram acréscimo no TSST quando produzidos com solução nutritiva resfriada. Esse fato, provavelmente, está relacionado às diferenças genéticas de cada variedade em relação às diferentes temperaturas do ambiente radicular.

TABELA 5. Desdobramento das médias do teor de sólidos solúveis totais (TSST) do suco extraído dos pseudofrutos do morangueiro cultivado em hidroponia tipo NFT, em ${ }^{\circ}$ Brix.

\begin{tabular}{lcrc}
\hline \multirow{2}{*}{ Variedades (V) } & \multicolumn{2}{c}{ Temperatura da Solução Nutritiva (T) } & \multirow{2}{*}{ Teste F } \\
\cline { 2 - 3 } & Temperatura Ambiente & Resfriada & \\
\hline Campinas & $5,28 \mathrm{Aa}$ & $5,36 \mathrm{Ba}$ & $0,31^{\mathrm{NS}}$ \\
Sweet Charlie & $5,20 \mathrm{Ab}$ & $6,11 \mathrm{Aa}$ & $34,16^{* *}$ \\
\hline Teste F & $0,23^{\mathrm{NS}}$ & $23,08^{* *}$ & \\
\hline DMS & \multicolumn{3}{c}{} \\
C.V. $(\%)$ & 0,35 & \\
S. & 4,02 & \\
\hline
\end{tabular}

${ }^{1}$ Médias seguidas pela mesma letra maiúscula na coluna e minúscula na linha não diferem entre si.

** Significativo pelo teste $\mathrm{F}$ ao nível de $1 \%$ de probabilidade.

NS Não significativo pelo teste F.

\section{CONCLUSÕES}

A variedade "Sweet Charlie" apresentou melhores resultados para peso médio dos pseudofrutos, diâmetro médio longitudinal, diâmetro médio transversal, número médio de pseudofrutos e produtividade que a variedade Campinas.

O resfriamento da solução nutritiva conferiu maior número de pseudofrutos colhidos e maior produtividade para a variedade "Sweet Charlie", não tendo afetado significativamente a variedade Campinas.

O resfriamento da solução nutritiva proporcionou aumento no teor médio de sólidos solúveis totais no suco extraído dos pseudofrutos produzidos somente para a variedade "Sweet Charlie".

Sendo assim, a técnica do resfriamento da solução nutritiva foi viável para a variedade "Sweet Charlie", não tendo afetado as variáveis de produção e qualidade da variedade Campinas.

\section{AGRADECIMENTOS}

Os autores agradecem à FAPESP (Fundação de Amparo à Pesquisa do Estado de São Paulo), pelos recursos de auxílio à pesquisa concedidos (Processo $\mathrm{n}^{\circ}$ 98/6889-8), tornando possível a realização deste trabalho científico.

\section{REFERÊNCIAS BIBLIOGRÁFICAS}

CASTELLANE, P.D.; ARAÚJO, J.A.C. de. Cultivo sem solo - Hidroponia. Jaboticabal: FUNEP, 1994. $43 \mathrm{p}$.

CAMARGO, L.S.; PASSOS, F.A. Morango. In: FURLANI, A.M.C.; VIÉGAS, G.P. O melhoramento de plantas no Instituto Agronômico. Campinas: Instituto Agronômico, 1993. p.411-32. 
CUNHA, R.J.P.; BIAGGIANI, L.H.M. Comportamento de cultivares e híbridos de morangueiro. Horticultura Brasileira, Brasília, v.8, n.2, p.25-6, 1990.

DODD, L.C.; HE, J.; TURNBULL, C.G.N.; LEE, S.K.; CRITCHLEY, C. The influence of supraoptimal root-zone temperatures on growth and stomatal conductance in Capsicum annum L. Journal of Experimental Botany, Oxford, v.51, n.343, p.239-48, 2000.

FERNANDES JÚNIOR, F. Produção do morangueiro em solo, hidroponia NFT e colunas verticais com substrato. 1994. 86 f. Dissertação (Mestrado em Nutrição de Plantas) - Instituto Agronômico de Campinas, IAC, Campinas, 1994.

FOSSATI, C. Como praticar el hidrocultivo. Madrid: EDAF, 1986. 174 p.

FURLANI, P.R.; SILVEIRA, L.C.P.; BOLONHEZI, D.; FAQUIN, V. Estruturas para o cultivo hidropônico. Informe Agropecuário, Belo Horizonte, v.20, n.200-201, p.72-80, 1999.

GUSMÃO, M.T.A. de. Análise do comportamento da cultura do morangueiro (Fragaria x ananassa Duch.) em condições de cultivo hidropônico. 2000. 60 f. Dissertação (Mestrado em Produção Vegetal) - Faculdade de Ciências Agrárias e Veterinárias, Universidade Estadual Paulista, Jaboticabal, 2000.

HE, J.; LEE, S.K. Growth and photosynthetic characteristics of lettuce (Lactuca sativa L.) under fluctuation hot ambient temperatures with the manipulation of cool root-zone temperature. Journal of Plant Physiology. Stuttgart, v.152, p.387-91, 1998.

LARCHER, W. Ecofisiologia vegetal. São Paulo: EPU, 1986. 319 p.

LEE, S.K.; CHEONG, S.C. Inducing head formation of iceberg lettuce (Lactuca sativa L. ) in the tropics though root zone temperature control. Tropical Agriculture, Surrey, v.73, p.34-42, 1996.

LIETEN, F. Methods and strategies of strawberry forcing in central Europe: historical perspectives and recent developments. Acta Horticulturae, Wageningen, n.348, p.158-70, 1993.

LINARDAKIS, D.K.; MANIOS, V.I. Hydroponic culture of strawberries in plastic greenhouse in a vertical system. Acta Horticulturae, Wageningen, n.287, p.317-26, 1991.

MORGAN, L. Nutrient temperature, oxygen and pithier in hydroponics. Disponível em: <http://www.quickgrow.com>. Acesso em: 28 março 2002.

PASSOS, F.A. Desenvolvimento de cultivares de morangueiro. In: SIMPÓSIO SOBRE A CULTURA DO MORANGUEIRO, 1., 1986, Cabreúva. Anais.... Jaboticabal: FUNEP, 1999. p.1-14.

RONQUE, E.R.V. A cultura do morangueiro: revisão e prática. Paraná: EMATER, 1998. 206 p.

TAKEDA, F. Strawberry production in soiless culture systems. Acta horticulturae, Wageningen, v.1, n.481, p.289-95, 1999.

VILLELA JUNIOR, L.V.E.; ARAÚJO, J.A.C. de; FACTOR, T.L. Comportamento do meloeiro em cultivo sem solo com a utilização de biofertilizante. Horticultura Brasileira, Brasília, v.21, n.2, p.1537, 2003.

VOLPE, C.A.; MINCHIO, C.A.; BARBOSA, J.C.; ANDRÉ, R.B. Análise da precipitação mensal em Jaboticabal (SP). Ciência Agronômica, Jaboticabal, v.4, n.2, p.3-5, 1989. 